\title{
Markets for Nutrition: What Role for Business?
}

\author{
John Humphrey and Ewan Robinson*
}

\begin{abstract}
Policymakers are increasingly seeking to use food systems to help reduce rates of chronic undernutrition and to use markets to deliver nutrient-rich foods to vulnerable populations. This article examines how this might be achieved, drawing lessons from three intervention types: ready-to-use therapeutic foods (RUTFs), mandatory fortification and voluntarily fortified products. We find that a common set of constraints tends to inhibit markets from delivering nutrition and makes it difficult to reach populations at the 'bottom of the pyramid'. Overcoming these constraints requires a shift from working at the level of individual businesses to that of market and food systems. It also suggests a need for renewed focus on the effectiveness of products in reaching key groups, on the informal markets that serve the poor and on the inherent complexity of market systems. These findings suggest that food and nutrition policies and partnerships should be based on principles of experimentation and adaptive learning.
\end{abstract}

\section{Introduction}

Human nutrition is now recognised as a central and persistent challenge for global development, and improving nutrition is seen as a key priority for reforming food and agricultural markets. ${ }^{1}$ At the global level, policy debates have also increasingly emphasised the potential for increased private sector involvement in initiatives addressing nutrition problems. While there are many contributors to poor nutrition status (disease, sanitation, caring practices, food, etc.), this article concentrates on the role of food and market-based approaches to making nutrientrich foods more available and accessible to the poor. Malnutrition encompasses multiple conditions, including acute malnutrition (a lack of calories or, most simply, hunger), chronic undernutrition (insufficient intake and retention of crucial micronutrients such as iron or vitamin A) and overnutrition (a range of diseases stemming from over-consumption of calories and fats). All three forms of malnutrition inflict severe damages on human health, wellbeing and economic productivity. This article, however, focuses specifically on chronic micronutrient deficiencies (hereafter referred to simply as 'undernutrition'), reflecting both the massive scale of these deficiencies, which affect one quarter of all children under five (de Onis,
Blössner and Borghi 2012), and contribute to one in three child deaths (UN Inter-Agency Group for Child Mortality Estimation 2011) and the specificities and complexities of micronutrient undernutrition. While reducing overnutrition is also a crucial global priority, the challenges encountered are quite different and not addressed here.

This article looks at what private sector initiatives need to achieve in order to enhance consumption of micronutrient-rich foods. It examines how development agencies, government, civil society organisations and businesses themselves might accomplish this. It also suggests some broader lessons that the case of using markets to reduce undernutrition can contribute to debates about the role of businesses and markets in providing social goods. A large number of agriculture-based initiatives have tried to tackle this problem through increasing the production of nutrient-rich foods by poor farm households and by encouraging consumption of at least some of this production on-farm (see, for example, Le Cuziat and Mattinen 2011). Nevertheless, many poor households secure all or part of the food they consume through market purchases, and the urban poor and rural non-farm households are 
clearly dependent on markets for securing household food supplies. Less obvious, but equally important, is the fact that many farm households purchase food to supplement their own production for some or all of the year.

The increasing emphasis on private sector involvement in food and nutrition reflects a more general trend to identify the contributions that businesses can make to development efforts. It also stems from the view that market-based approaches are more effective than public sector alternatives, and can achieve more lasting impacts, since they aim to generate commercial markets that continue without public support. This perspective proposes that the role of donor agencies and governments is to act as facilitators of markets. Both the UK Department for International Development's (DFID) 2011 position paper on undernutrition and the United States Agency for International Development (USAID) Feed the Future programme have argued in favour of mobilising greater private sector involvement in development initiatives around food and agriculture:

We believe the private sector has a much greater role to play in tackling undernutrition through the food they produce, their ability to reach people in remote areas and their communications, marketing and distribution capacity (DFID 2011: 23).

The private sector brings necessary financial resources, human capital, technological resources and intellectual property, market access, cutting-edge business practices towards addressing hunger and undernutrition (USAID 2010: 6).

So what activities by the private sector should donors and governments be supporting or encouraging? Private actors, from multinational corporations to small social enterprises, have proposed a wide range of options. A presentation by David Yach, Senior Vice President Global Health and Agricultural Policy at PepsiCo lists eight ways in which large food companies could help reduce worldwide undernutrition, including investment in agriculture, support for fortification programmes, complementary feeding initiatives, new business models, low-cost nutritious foods and advocacy for nutrition-friendly trade policies (Yach 2011). The nutrition initiatives listed on the
Business Call to Action website ${ }^{2}$ include micronutrient sprinkles and powders, provision of safe and affordable water, support for small farmers, micro-irrigation, hygiene products and fortified products for children.

In fact, there are many agendas around food and nutrition. Different types of businesses may well have different agendas, reflecting both their specific interests and their understanding of the impacts of different courses of action. Some businesses might favour liberalising food imports as the best strategy for increasing food availability and reducing prices (especially if they are engaged in food trading), while others might favour promoting domestic production and import substitution, particularly if they had investments in local productive capacity. The same divergences in interests and priorities can also be found within governments. Ministries of Agriculture may have different views about the importance of nutrition and how to promote it compared to Departments of Health or Rural Development. The way in which the priorities of the G8's New Alliance for Food Security and Nutrition has evolved in the last two years shows how both governments and businesses shape food and nutrition agendas. In this context, it is important to identify what types of business interventions in food markets are likely to lead to substantial reductions in micronutrient undernutrition (and those which are not) and to make such information available to parties aiming to shape policy directions and priorities.

This article argues that the priority for marketoriented interventions should be to work in and through markets that are used by the poor to source food, including informal markets, and that these interventions should primarily address market constraints and market incentives, rather than focus on individual products and businesses. It argues further, that the challenges facing businesses are severe as they try to build markets for nutrient-rich foods, while at the same time ensuring these foods are affordable and available to the most disadvantaged populations. This leaves a crucial role for public and non-profit actors in creating markets for nutrient-rich foods.

\section{Market challenges and development objectives}

Large amounts of food are produced and distributed through market relationships in developing countries, but it is clear from the 


\section{Preconditions for improving nutrition}

1 Provide nutritional value. Food must contain key micronutrients that address deficiencies in the population and these must be maintained throughout the value chain.

Foods must also be eaten in the right quantities and nutrients must be absorbed in the body. ${ }^{6}$

2 Food reaches undernourished people. It is eaten by the most affected populations.

The most important groups are pregnant and lactating women and children under the age of two, often known as the ' 1,000 days' group.

The poorest groups are also much more vulnerable to undernutrition.

3 Guarantee of nutritional quality. Consumers must believe the claims made about the benefits of products. This is a necessity when nutrient-rich products are more expensive than similar, less nutritious products.

Achieving this is difficult because nutrients are 'invisible', particularly in processed foods that have been fortified with added nutrients.

4 Consumers value nutrition/are willing to pay. Potential consumers must value good nutrition and health, recognise the nutritional benefits of the food and be willing to pay for it, and to replace existing foods in their diets.

\section{Business model challenges}

Maintaining nutrient content. Designing a product with sufficient nutritional value and then ensuring that this value is maintained through processing, storage and distribution.

Correct use of product. Motivating and informing consumers to use the product in the correct way (particularly difficult when a food must be eaten daily to be effective).

Targeting. The food must be promoted in such a way that it is consumed by the population groups that most need it.

Distribution. It must be distributed to the places where the poor can obtain it without undue difficulty.

Affordability. The food must be sold at very low prices so that the poor can afford to purchase it regularly.

Fraudulent and pass-off products. In open markets, there are incentives to pass off non-nutritious foods as nutritious ones in order to sell them at a higher price. This undermines business incentives.

Product differentiation. Businesses need to find ways to convince consumers that claims about their products are true and to distinguish their products from inferior or fraudulent copies.

Nutrition awareness. In business terminology, nutrition is a 'push good': consumers are unaware of the value it provides and may have preferences for foods that are not nutrient-rich. Changing understanding and preferences is a challenge, since a single business can rarely capture the value of investments made to raise awareness. This role is often played by public education.

Consumer preferences. Businesses must also meet consumer preferences for food taste, texture, packaging and preparation time.

Source Authors' own.

alarmingly high rates of micronutrient deficiencies and low consumption of nutrientrich foods in many countries that markets are not providing good nutrition for low-income populations. ${ }^{3}$ Nutrient-rich foods are available in nearly all countries, but very often they are not consumed by poor households (Anim-Somuah et al. 2013; Temu et al. 2014). The challenge for market-based approaches is to make nutrientrich foods available to undernourished people in 
a form that they (or key decision-makers in the households $)^{4}$ are willing and able to buy, while providing adequate incentives to businesses to enter these value chains. In other words, marketbased interventions must address the needs of businesses (of all types and sizes) to develop sustainable business models, while also substantially reducing nutritional deficiencies. ${ }^{5}$

Meeting these two requirements in tandem is very difficult. Table 1 indicates how they are linked through four key issues, identifying the development priorities in the left-hand column, and the business implications on the right. Many of these challenges are not unique to nutrition they also impact efforts to market other kinds of products to low-income consumers, an approach often referred to as the 'bottom of the pyramid' (as discussed by Koh, Hegde and Karamchandani 2014). Yet what makes markets for nutrition particularly complex is the overlap of the common challenges at the bottom of the pyramid, such as the high costs of distribution, with the specific requirements for nutrition, such as reaching the most vulnerable populations, educating consumers and motivating them to alter behaviours and providing a guarantee of the 'invisible' nutritional quality of foods. The relationship among these challenges is now discussed.

None of the business challenges identified in Table 1 are insurmountable. It has been argued, for example, that even very poor consumers may be willing to buy more expensive products if they are convinced that these products have value (for example, in protecting their children against blindness, a consequence of chronic vitamin A deficiency) (Hystra 2014: 18-20). However, what makes these challenges complex is that they must generally be addressed in tandem and with minimal increase in cost. While certain strategies are available to individual businesses for overcoming some of the above challenges, these tend to entail high costs or differentiating products as premium goods, which puts them out of reach for the poor. Building distribution systems to reach poor populations is an example. Distributing to areas where poor people live especially rural areas - entails high transportation costs for products that are centrally produced by a large manufacturer (Bruyeron et al. 2010). This problem is compounded by the need to target situations of greatest risk - in particular the 1,000-day window from conception to two years of age, which means focusing on the nutritional status of infants and women before pregnancy and during the same 1,000-day period. This relatively small and specific population means a smaller potential market for businesses and often requires specific distribution channels (such as door-todoor sales targeting mothers). Again, the result is higher costs. A comparison of seven businesses selling fortified complementary foods ${ }^{7}$ to lowincome consumers found that distribution and marketing costs typically amounted to $50-70$ per cent of the final product price (Hystra 2014: 34-5). These factors make it more difficult for businesses based on centralised production to serve these groups. For this reason, the ability of informal sector providers to operate close to the poor could be a considerable advantage, so long as the quality and safety of products can be assured, as will be discussed below.

Meanwhile, guaranteeing nutritional quality creates an additional set of challenges. The nutritional quality of many foods (particularly processed foods) is 'invisible'; hence there is a profound information asymmetry between producers (who know the ingredients/nutrient content of the product) and consumers, who cannot assess the nutritional quality of what they are buying. This has the parallel effects of creating incentives for some firms to attempt to 'pass off' foods of low nutritional quality as 'nutritious' (for example, claiming that a product is fortified when in fact it is not), while at the same time undermining consumers' trust of producers' claims. Firms selling good quality products cannot differentiate them from those that are pretending to do $\mathrm{So}^{8}$ - particularly a problem since nutrient-rich foods tend to be more expensive. Individual businesses can respond to this through premium branding and product differentiation - as discussed in Section 3.3. However, this solution tends to compromise the affordability of products. The overall result is low investment in nutrient-rich foods - especially in the market segments that serve the poor.

These examples highlight the overlapping challenges of marketing nutrient-rich foods to the poor. Strategies such as developing new distribution systems, good quality packaging, brand development and advertisement and nutrition awareness all raise costs, undermining the fundamental requirement that the products are affordable to the poor. These problems are 
exacerbated by the complex market environments found in most developing countries, where a combination of formal and informal actors, poorly integrated value chains and ineffective regulation can further increase costs and risk, both for businesses and for wouldbe market interventions by public sector actors. ${ }^{9}$ The result is a gulf between the efficacy of certain foods for mitigating undernutrition and the effectiveness of their use in practice. There are numerous products and approaches that have been demonstrated to reduce or reverse undernutrition - when undernourished children or adults eat them appropriately. But these products will not become viable market solutions without a context where businesses can earn commercial returns by delivering these products to undernourished people. Suchdev et al. (2010: 1223-4) observe that although 'numerous efficacy trials... have demonstrated that MNP [micronutrient powder] use is associated with a significant reduction in the incidence of anaemia... the effectiveness of MNP programmes in real-world settings has rarely been assessed'.

\section{Intervening in food markets}

Responses to the challenges outlined in the previous section could be developed by particular enterprises. However, we argue that sustainably addressing these challenges most often requires analysis and response not at the level of individual businesses, but at the level of the food system, which encompasses both businesses linked in value chains and the public and private institutions, rules and norms within which transactions take place. Addressing the challenges requires a combination of market systems interventions, public regulation and divisions of labour between for-profit enterprises, social enterprises and public actors. To illustrate this, we consider three different types of fortified food products: ready-to-use therapeutic foods (RUTFs), food staples fortified compulsorily by government regulation (mandatory fortification) and foods to which businesses choose voluntarily to add fortificants. These examples were chosen for two reasons: first, fortification in its various forms has attracted substantial attention from both businesses and policy interventions, providing a pool of empirical experience from which lessons can be drawn; second, these products serve to illustrate the interrelation among the challenges described above, and how market interventions can potentially simplify these challenges. ${ }^{10}$

\subsection{The success of RUTFs: a non-contested space}

Used to treat severe acute malnutrition, RUTFs are packaged food products that are extremely dense in energy and micronutrients; they are also specifically designed for public distribution systems. Analysing why the RUTF model has worked well helps to understand better how the challenges discussed earlier can be met, and highlights the specificity of the conditions for the successful distribution of RUTFs. An analysis of RUTFs by Lybbert (2011) shows how collaborations between businesses, international agencies and governments in the production and delivery of these products serve to minimise the challenges outlined above. Key to the RUTF model is that the United Nations Children's Fund (UNICEF), Médecins Sans Frontières (MSF) and the World Food Programme (WFP), public agencies with a specific mandate to reduce undernutrition, have an effective monopoly over distribution. This gives them considerable power, which they use to control product specifications and branding - and to ensure end products meet strict nutritional standards. Private companies are responsible for manufacturing the RUTFs, but operate under the supervision of these agencies, and the products are distributed for free in emergency situations.

This model achieves strict control over product quality and nutrient content. No competing products exist in this particular market. Further, the product is provided free, which enables the agencies to target the needy and avoid the issues of affordability and willingness to pay. The lead organisations guarantee the integrity of the product, enable rapid build-up to scale and provide businesses (in some cases) with a tacit pre-market commitment that reduces investment risk (Fite 2013).

This model depends upon the reputation of the lead agencies, their power to establish a de facto monopoly on distribution (and hence maintain standards) and their capacity to access the financial resources needed to sustain free distribution. This means that the product operates in a non-contested space. ${ }^{11}$ As Lybbert demonstrates conclusively, it is these factors, not the physical characteristics of the product that account for the success of the model. He shows that the dynamics of a contested market (in which multiple actors could vie for market share) 
for a similar product, used preventively and purchased on the open market, would be very different and subject to many of the challenges outlined in Table 1 .

RUTFs are not the only example of combining business involvement with a public role on the distribution side. Public distribution can be used to promote the targeting of particular groups, as is the case with school feeding programmes, or to target the poor in general, through such initiatives as the Universal Stores Corporation in Pakistan, which markets foods at subsidised prices to low-income consumers. The purpose of such programmes may be to provide a targeted subsidy, but they may also provide scale economies, guaranteed outlets to producers and some reassurances to consumers about nutritional quality (depending upon the credibility of the public entity responsible).

\subsection{Mandatory fortification: covering the whole market}

Food fortification is one of the most widely-used and promoted food-based strategies to combat undernutrition. It involves adding specific micronutrients to foods. ${ }^{12}$ Mandatory fortification uses the force of law to make the addition of micronutrients compulsory in certain products (these are typically widely-used staples such as flours, cooking oil, salt, etc.). This approach is a highly cost-effective means of introducing fortification for a large volume of products, and has the potential to reach large numbers of people. It potentially meets many of the challenges listed above - including nutrition awareness, willingness to pay, consumer choice and the asymmetric information problem - by eliminating non-fortified products from the market. To the extent that mandatory fortification leads to widespread consumption of the product, it should reach some of the priority target groups for nutrition interventions (particularly pregnant and lactating women). Finally, by focusing on widely-used products, it takes advantage of existing, well-developed, high-volume distribution systems.

Nevertheless, mandatory fortification faces two big challenges. First, can nutrient quality be guaranteed? Food processing companies may not have the capabilities needed for consistent fortification, and they can cut costs by adding less than the required quantities of fortification. Governments may lack the means or the will to enforce regulations. A recent study of mandatory fortification of vegetable oil, sugar and cereal flours in Nigeria found - on the basis of sampling products available at retail outlets - that between 60 and 90 per cent of products fail to meet the fortification standard (Ogunmoyela et al. 2013). Developing the necessary regulatory framework at both business and government level to enforce fortification regulations requires state capacities that are lacking, not only in Nigeria, but also in other countries (see, for example, the case of Pakistan, Planning Commission 2012).

Second, mandatory fortification may fall short of universal coverage, and is particularly bad at covering the populations most vulnerable to micronutrient deficiencies. In Tanzania, mandatory fortification for maize flour is being introduced among large manufacturers, but less than one fifth of people in the bottom three wealth quintiles purchase maize flour from these businesses (Robinson et al. 2014b). Instead, most consumers source their flour from informal markets. This not only undermines the reach of fortification programmes, but may also undermine the economic basis of the participation by large flour millers. There may be substitutes for fortified products (maize flour or cassava rather than wheat flour, for example), and the poor may purchase such low-cost alternatives disproportionately, even prior to fortification. At the same time, extending fortification to smallscale food processors would require development of these firms' capabilities, the expansion of the regulatory framework to cover a much larger number of firms and supported regulatory mechanisms capable of working with small enterprises with low degrees of formality.

Both of these issues have been challenges even for fortification schemes using mostly large firms. A USAID-funded programme in Tanzania found that it was much more difficult than anticipated to develop the fortification capacities of small businesses. After running for two years, the programme had managed to register just five businesses with the state authority (Robinson $e t$ al. 2014b), which was just the first step in the process.

\subsection{Non-mandatory fortification: contested markets}

A wide array of fortified, processed foods are produced in developing countries, some of which are targeted specifically at the undernourished 
(for example, complementary foods for infants), while others are marketed to broader populations (for example snack bars, breakfast cereals and instant noodles). However, one clear strategy for developing such products is to target them at higher-income populations and identify them as being premium products. Nestlé's complementary food for infants, Cerelac, is a good example. It occupies a dominant position at the top end of the infant food market in many West African countries, but being presented and priced as a premium brand, it is consequently too expensive for poor people to purchase and use in the quantities needed for infant health (for a discussion of this model, see Masters, Kuwornu and Sarpong 2011). ${ }^{13}$

Maintaining safety and nutrient content while achieving the price points and level of consumer confidence needed to generate willingness to pay is much more difficult. This is where public intervention to promote particular nutrientdense foods can be justified. There are two distinct arguments in favour of this. First, the social benefits of good nutrition (in terms of health, productivity, etc.) may warrant the cost of public intervention. Public intervention can also increase equity, by providing specific benefits to the most disadvantaged. In this situation, interventions aimed at increasing the availability of nutrient-rich foods are on a par with the provision of health services or social protection schemes. Second, public intervention can help to overcome the market failures which are preventing viable business models from emerging. Four common market failures that are found in contested markets and how they might be addressed are:

\section{The start-up costs associated with}

innovation, particularly as nutrition markets are complex (many competing products and providers, uncertainty about acceptability, price points, low consumer awareness, etc.) and the benefits of discovering new markets may not be fully appropriable by the first mover. Interventions may defray some of the costs of innovation (for example, the role of the Global Alliance for Improved Nutrition (GAIN) in subsidising efficacy trials, in Sazawal et al. 2013) or reduce uncertainty and accelerate the achievement of scale through advance purchasing commitments and subsidised distribution.

\section{Supply chain inefficiencies and incomplete} markets. Innovation at the level of the firm or the product frequently involves simultaneous initiatives along the value chain (upstream, downstream or in service functions). If simultaneous actions are difficult to coordinate, public intervention may be required to generate cooperation and find ways of overcoming value chain obstacles. This may be in the form of subsidies, or sponsoring cooperation with non-profit organisations such as social enterprises to take the lead.

\section{Lack of transparency in markets. Nutrition} markets are subject to false claims and fraudulent products. In Nigeria, one company found that sales of one of its leading nutrition products were significantly higher than its total output, implying considerable circulation of fake products (Nwuneli et al. 2014). The level of market disinformation can be reduced by public regulation; public endorsement may increase the prospects of genuine products. Similarly, schemes such as the GAIN premix facility ${ }^{14}$ reduces transaction costs of businesses in fortification.

4 Distribution costs. A number of studies have pointed to the very high costs of distribution incurred in trying to reach the poorest, or those most at risk of undernourishment (Hystra 2014; Koh et al. 2014). This part of the delivery system could be entrusted to public or social enterprises, or hybrid models that use local distributors in the community. Here, we see the importance of dividing activities in the value chain among the organisations most capable of carrying them out.

Overall, many initiatives focusing on low-cost fortified foods in contexts where fortification is not mandatory have been in the form of partnerships between the public and private sectors, intended to provide technical support, defray costs or reduce risk. However, it is unclear whether this form of support provides a basis for long-term sustainability. In a number of cases, despite public agencies contributing to the development and other start-up costs of fortified food products, businesses have not been able to continue producing these products once public procurement ended (Maestre et al. 2014; Nwuneli et al. 2014; Robinson et al. 2014a). The challenge, 
then, is to target public involvement in a way that addresses (or simplifies) the fundamental business challenges described in Section 2.

\section{Conclusions: making food markets nutrition- friendly}

At first glance, mobilising businesses to support efforts to reduce undernutrition might appear to be a relatively simple challenge. Businesses need simply to produce nutrient-rich food and sell it to poor people, and an array of businesses ranging from multinational corporations to microenterprises have extensive capacities in developing, producing and marketing food products. Yet, as the discussion above shows, successful market solutions turn out to require much more than good products and efficient business operations. The analysis of three mechanisms for delivering nutrient-rich food to the undernourished shows that the challenges involved are, in fact, complex and systemic in nature. These are reflected in the observed gap between the potential of particular products to improve nutritional status - as indicated by efficacy studies - and the actual effectiveness of these products when distributed through realworld markets (Suchdev et al. 2010). What insights do we gain from this analysis?

The first insight is that market-based approaches encounter severe problems in distribution and marketing. Reaching the poor tends to increase distribution costs, and markets for nutrition are made complex by the 'invisibility' of nutritional content, creating easy targets for misleading or fraudulent claims. Two of the three types of delivery mechanisms discussed above take some of these problems out of the equation. The RUTF model does not rely on market-based distribution at all (although the private sector has a central role in product manufacture), while mandatory fortification aims to remove uncertainty about nutrient content through public regulation. These examples point to the importance of considering the contributions of public and non-profit organisations to food marketing and distribution.

The second insight is that many of the challenges facing businesses are outside their immediate control: they reside in the value chain, the regulatory environment or the characteristics of market institutions. Some large firms may have the resources and capabilities to overcome some of these problems (for example, by intervening actively to structure supply chains). Yet, these options are generally not available to smaller businesses. Furthermore, change focused on a single company and its value chain - in the absence of more systemic efforts - risks creating segmented markets; wealthier groups may access nutrient-rich products, while the poor continue to source from low-quality markets. ${ }^{15}$ Therefore, improving the performance of food markets should be framed in terms of market development and market systems approaches, rather than focus on individual businesses.

The third insight is that, given these complex market problems, assessments of the effectiveness of initiatives need to be based on real-world market conditions. While it is costly and complicated to verify that these interventions improve nutrient status, assessment should at the very least verify that the foods being promoted are reaching poor households, and preferably show that they are being consumed by household members that are most in need of them.

The fourth insight is that addressing undernutrition through markets involves intervening in what is a 'complex system', as discussed by Jenal and Cunningham (this IDS Bulletin). There are a large number and diversity of actors involved in food value chains, and many conditions must be satisfied in order for products to gain traction in the market and reach the people most vulnerable to undernutrition. As a result, it is difficult to predict or model how markets and market actors respond to policy initiatives. This complexity also arises from the political and institutional contexts of nutrition policy and nutrition markets. Policymakers (working not only on nutrition policy, but also the related fields that influence food markets) are also subject to political pressures and vested interests. There is, therefore, a clear need to frame food market interventions as both market systems interventions (Springfield Centre 2014) and as interventions in a complex policy system consisting of multiple policy actors and interests (USAID 2014).

The final insight derives from the recognition of market system complexity and the challenges of reaching the groups most at risk of undernutrition through food market initiatives. Private sector initiatives focusing on the bottom 
of the pyramid should begin by concentrating on the markets that poor people use. In many countries the majority of poor people source food from informal producers and traders, and it would be wrong to assume that informal sector food provision will be replaced by modernised value chains. Evidence from African countries (Robinson et al. 2014a; Vorley, Pozo-Vergnes and Barnett 2012) does not support such an idea. As a result, the challenge is to work with and through the informal sector to improve its efficacy. Regulating informal activities is notoriously difficult, and will require that donors, governments and larger businesses increase their own capacity in this area. In food safety - which is in many ways analogous to the challenge of improving nutrient content - pilots have found that identifying enterprises with best practices

\section{Notes}

* This article draws on research funded by UK DFID. The views expressed do not necessarily reflect the UK government's official policies. The authors gratefully acknowledge critical input to this article from Jodie Thorpe and Elise Wach.

1 Beyond food, other initiatives are also critical to reducing undernutrition, particularly access to health care, clean water and sanitation, and women's empowerment. The present discussion focuses just on food.

2 www.businesscalltoaction.org.

3 These are problems that affect firm performance but are not under the direct control of the firm - what Monitor Inclusive Markets describe as 'business ecosystem constraints' (Koh et al. 2014).

4 There is a gendered element to this. Bruyeron et al. note that in Burkina Faso sales volumes for micronutrient-rich flours for infants seemed limited by 'the capacity to persuade fathers (who manage the bulk of family funds) to spend money on special foods for infants... Community workers report that it is more difficult to persuade fathers than mothers to use the product' (2010: S162).

5 Of course, this is a simplification. Development agents want to achieve nutritional improvements, but at the same time as cost effectiveness, long-term sustainability, etc. Businesses may have varying motives with respect to the position of particular products within their full portfolio. and providing training and support lead to better food quality and safety than do 'crack downs' on the informal sector (Grace 2014).

This article has identified significant challenges that face attempts to mobilise businesses in initiatives to tackle the widespread problem of undernutrition in developing countries. It has highlighted the complexities of markets for nutrition-rich products, and a variety of approaches that might be used to improve the poor's access to nutrient-rich foods. The role of policy in this context should be to develop policies and programmes aimed at achieving systemic change in the functioning of value chains and food markets, and ensuring that initiatives have a demonstrable dietary impact for people vulnerable to undernutrition.

6 Dietary factors - such as eating starchy foods with high levels of phytates - and health conditions - such as chronic, low-level infections - can severely reduce the body's capacity to absorb micronutrients in foods.

7 Complementary foods are products intended for consumption by infants from 6 to 24 months, alongside breast milk.

8 Businesses can and do overcome this problem by positioning products as premium brands with high prices, but this places them out of reach for low-income populations.

9 Clearly there is also tremendous variation in these effects across and within countries.

10 Our focus on fortified products in this article is not because we view it as superior to promoting dietary diversity for foods naturally rich in nutrients. Fortified products are chosen because they highlight the business challenges that appear particularly starkly. Many of the lessons apply to non-fortified foods distributed via markets.

11 The idea of contested and non-contested spaces is taken from the work of Büthe and Mattli (2011) on the privatisation of regulation and the contrast between competitive and non-competitive standards.

12 Fortification 'is the practice of deliberately increasing the content of an essential micronutrient, i.e. vitamins and minerals (including trace elements) in a food, so as to improve the nutritional quality of the food supply and provide a public health benefit with minimal risk to health' (Allen et al. 2006: xxvii). 
13 Research in West Africa found similar examples of premium, branded fortified products aimed at the more affluent household. See, for example, the case of Lisabi Mills in Nigeria (Nwuneli et al. 2014). 14 http://gpf.gainhealth.org.

\section{References}

Allen, L.; de Benoist, B.; Dary, O. and Hurrell, R. (eds) (2006) Guidelines on Food Fortification with Micronutrients, Geneva and Rome: WHO and FAO, www.who.int/nutrition/publications/ guide_food_fortification_micronutrients.pdf (accessed $3 \overline{1}$ January 2015)

Anim-Somuah, H.; Henson, S.; Humphrey, J. and Robinson, E. (2013) Strengthening Agri-food Value Chains for Nutrition: Mapping Value Chains for Nutrient-dense Foods in Ghana, Evidence Report 2, Brighton: IDS

Bruyeron, O.; Denizeau, M.; Berger, J. and Trèche, S. (2010) 'Marketing Complementary Foods and Supplements in Burkina Faso, Madagascar, and Vietnam: Lessons Learned from the Nutridev Program', Food and Nutrition Bulletin 31.2 (supplement): S154-67

Büthe, T. and Mattli, W. (2011) The New Global Rulers: The Privatisation of Regulation in the World Economy, Princeton NJ: Princeton University Press

de Onis, M.; Blössner, M. and Borghi, E. (2012) 'Prevalence of Stunting among Pre-school Children 1990-2020', Public Health Nutrition 15.1: 142-8

DFID (2011) Scaling up Nutrition: The UK's Position Paper on Undernutrition, London: Department for International Development, www.dfid.gov.uk/Documents/publications 1/ scal-up-nutr-uk-pos-undernutr.pdf (accessed January 2015)

Fite, T.S. (2013) Pepsicoco: Partnering with International Development Organizations to Scale up Chickpea Production and Fight Malnutrition in Ethiopia, New York NY: United Nations Development Programme

Grace, D. (2014) 'Food Safety in Informal Markets', presentation made at IFPRI 2020 Policy Consultation and Conference, Addis Ababa, May, www.slideshare.net/ILRI/foodsafetymay2014-grace (accessed 31 January 2015) Hystra (2014) Marketing Nutrition for the Base of the Pyramid: Hystra, hystra.com/s/Hystra_Accessto-Nutrition-4pp-Web-99vf.pdf (accessed 31 January 2015)
15 It may, in fact, be in the interests of large companies to devise mechanisms of coping with these problems that do not benefit other companies, as this would facilitate competition.

Koh, H.; Hegde, N. and Karamchandani, A. (2014) Beyond the Pioneer: Getting Inclusive Industries to Scale, Mumbai: Monitor Inclusive Markets, www.beyondthepioneer.org (accessed 30 June 2014)

Le Cuziat, G. and Mattinen, H. (2011) Maximising the Nutritional Impact of Food Security and Livelihood Interventions: A Manual for Field Workers, New York NY: ACF International, www.actionagainsthunger.org/publication/ 2011/07/maximising-nutritional-impact-foodsecurity-and-livelihoods-interventions (accessed 30 April 2012)

Lybbert, T. (2011) 'Hybrid Public-Private Delivery of Preventative Lipid-based Nutrient Supplement Products: Key Challenges, Opportunities and Players in an Emerging Product Space', SCN News 39: 32-9

Maestre, M.; Robinson, E.; Humphrey, J. and Henson, S. (2014) The Role of Businesses in Providing Nutrient-rich Foods for the Poor: A Case Study in Tanzania, Evidence Report 66, Brighton: IDS

Masters, W.A.; Kuwornu, J. and Sarpong, D. (2011) Improving Child Nutrition through Quality Certification of Infant Foods: Scoping Study for a Randomized Trial in Ghana, London:

International Growth Centre, www.theigc.org/ publications/working-paper/improving-childnutrition-through-quality-certification-infantfoods (accessed 31 January 2015)

Nwuneli, N.; Robinson, E.; Humphrey, J. and Henson, S. (2014) The Role of Businesses in Providing Nutrient-rich Foods for the Poor: Two Case Studies in Nigeria, IDS Evidence Report 66, Brighton: IDS

Ogunmoyela, O.A.; Adekoyeni, O.; Aminu, F. and Umunna, L.O. (2013) 'A Critical Evaluation of Survey Results of Vitamin A and Iron Levels in the Mandatory Fortified Food Vehicles and Some Selected Processed Foods in Nigeria', Nigerian Food Journal 31.2: 52-62

Planning Commission (2012) Stakeholder Consultation Report on Regulatory Monitoring of Salt, Wheat Flour and Oil Fortification Programs in Pakistan, Islamabad: Planning Commission, 
Planning and Development Division, www.pc.gov.pk/hot\%20links/2012/Stakeholder \%20Consultation\%20on\%20Regulatory\%20 Monitoring.pdf (accessed 30 November 2014)

Robinson, E.; Akinyele, I.; Humphrey, J. and Henson, S. (2014a) Policy Options to Enhance Markets for Nutrient-dense Foods in Nigeria, IDS Evidence Report 66, Brighton: IDS

Robinson, E.; Temu, A.; Waized, B.; Ndyetabula, D.;

Humphrey, J. and Henson, S. (2014b) Policy

Options to Enhance Markets for Nutrient-dense Foods in Tanzania, IDS Evidence Report 90, Brighton: IDS

Sazawal, S.; Habib, A.A.; Dhingra, U.; Dutta, A.;

Dhingra, P.; Sarkar, A.; Deb, S.; Alam, J.; Husna, A. and Black, R.E. (2013) 'Impact of Micronutrient Fortification of Yoghurt on Micronutrient Status Markers and Growth a Randomized Double Blind Controlled Trial among School Children in Bangladesh', $B M C$ Public Health 13: 514

Springfield Centre (2014) The Operational Guide for Making Markets Work for the Poor (M4P) Approach (2nd Edition), London and Berne: DFID and SDC, www.beamexchange.org/en/ resource-detail/resource/167 (accessed 31 October 2014)

Suchdev, P.S.; Ruth, L.; Obure, A.; Were, V.; Ochieng, C.; Ogange, L.; Owuor, M.; Ngure, F.; Quick, R.; Juliao, P.; Jung, C.; Teates, K.; Cruz, K. and Jefferds, M.E.D. (2010)
'Monitoring the Marketing, Distribution, and Use of Sprinkles Micronutrient Powders in Rural Western Kenya', Food and Nutrition Bulletin 31.2 (supplement): S168-78

Temu, A.; Waized, B.; Ndyetabula, D.;

Robinson, E.; Humphrey, J. and Henson, S. (2014) Mapping Value Chains for Nutrient-dense Foods in Tanzania, IDS Evidence Report 90, Brighton: IDS

UN Inter-Agency Group for Child Mortality Estimation (2011) Levels \& Trends and Child Mortality: Report, New York NY: UNICEF, www.childinfo.org/files/Child_Mortality Report_2012.pdf (accessed 31 January 2015) USAID (2014) Local Systems: A Framework for Supporting Sustainable Development, Washington DC: ACDI/VOCA, www.usaid.gov/policy/localsystems-framework (accessed 9 February 2015) USAID (2010) Feed the Future Guide, Washington DC: USAID, www.feedthefuture.gov/guide.html (accessed 31 March 2013)

Vorley, B.; Pozo-Vergnes, E. and Barnett, A. (2012) Small Producer Agency in the Globalised Market: Making Choices in a Changing World, London and The Hague: IIED, HIVOS, Mainumby Nakurutu

Yach, D. (2011) 'The Role of the Private Sector in Improving Food Security and Nutrition', Policy Seminar Presentation made at IFPRI Washington DC, 7 September 2011 